\section{Marital status and physician-assisted suicide}

To the Editor,

In the first 2 years that Oregon's Death With Dignity Act has been operative, 43 people legally obtained and used lethal prescriptions to end their lives. ${ }^{1}$ Never-married and divorced persons were 4.2 and 3.2 times, respectively, more likely than married persons to use physician-assisted suicide. Unfortunately, the cross-sectional nature of the data precludes drawing any causal inferences from the findings. In addition, it is prudent not to draw any firm conclusions from such a small sample, and statistical analyses of so few cases are not particularly useful. Nevertheless, we give reasons why we believe never-married and divorced persons are more likely than married persons to take medication to end their lives.

Because most persons who have never married or are divorced are, by necessity, self-reliant, they may be devastated by any loss of their independence that accompanies a terminal illness. Thus, they may prefer to hasten their death rather than be overly dependent on others. Loss of autonomy and loss of control of bodily functions are strongly associated with physician-assisted suicide, and the vast majority of Oregonians who took the medication did so before becoming bedridden. ${ }^{1}$

According to a staunch opponent of physician-assisted suicide, people develop and maintain their sense of being valuable through relationships with others. ${ }^{2}$ It should not surprise opponents, then, that the weaker family and social networks and greater likelihood of being lonely that never-married and divorced people have may make them less willing than married persons to tolerate living with a terminal illness. In a study of terminally ill Canadians, patients classified as having a serious desire for death had significantly lower levels of family support than other patients. $^{3}$

Terminally ill single persons are probably less likely to receive assistance with everyday tasks, such as personal care and transportation, because they do not have a spouse to serve as their caregiver and, compared with married persons, they generally have less contact with their children. This may make their everyday life more difficult, thus increasing the likelihood that they hasten their death.

It should be easier for single persons to choose physician-assisted suicide because they do not have to consider the concerns of, or ramifications to, their spouse in deciding how to die. In addition, unmarried terminally ill elderly people are probably more susceptible to pressure (subtle and otherwise) to use physician-assisted suicide than married persons; con artists routinely target single elderly persons.

If physicians would ensure that their unmarried terminally ill patients were not isolated and received adequate assistance with their everyday needs, fewer persons would use physician-assisted suicide.

Dr Wineberg taught a course on physicianassisted suicide at Portland State University in 1998. M Purtzer was a graduate student in this course.

Howard Wineberg

1513 SE Oak St

Portland, OR 97214-1454

M Zoe Purtzer

School of Community Health

Portland State University

Portland, OR

Correspondence to:

Dr Wineberg

winebergh@hotmail.com

References

1 Sullivan AD, Hedberg K, Fleming DW. Oregon's Death with Dignity Act: The Second Year's Experience. Portland: Oregon Health Division; 2000.

2 Hamilton NG, Edwards PJ, Boehnlein JK, Hamilton CA. The doctor-patient relationship and assisted suicide: a contribution from dynamic psychiatry. $A m \mathrm{~J}$ Forensic Psychiatry. 1998;19:59-75.
3 Chochinov HM, Wilson KG, Enns M, et al. Desire for death in the terminally ill. Am J Psychiatry $1995 ; 152: 1185-1191$ 